\title{
Theoretical Prediction of p53 Gene Mutagenic Mechanism Induced by \\ Trans-4-hydroxy-2-nonenal
}

\author{
Dianxiang Xing ${ }^{\dagger, \star}$, Lixiang Sun ${ }^{\dagger}$, Robert I Cukier ${ }^{\S}$,Yuxiang Bu ${ }^{* \dagger, \S}$
}

Institute of Theoretical Chemistry, Shandong University, Jinan, 250100, P. R. China, School of Chemical Engineering, Shandong Institute of Light Industry, Jinan, 250100, P. R. China, and Department of Chemistry, Michigan State University, East Lansing, MI 48824, USA

\section{Supporting Information}

Table S1. Relative Energies $(\mathrm{kcal} / \mathrm{mol})$ for the Optimized Structures along the Reaction Pathway $^{a, b, c}$.

\begin{tabular}{|c|c|c|c|c|c|c|c|c|c|}
\hline ts1-a & I1-a1 & I1-a2 & ts2-a & I2-a & I2-a1 & ts3-1 & ts3-1' & 1 & $1^{\prime}$ \\
\hline \multirow[t]{2}{*}{27.44} & 1.93 & 1.76 & $(54.94)$ & -3.29 & -7.97 & 51.69 & 54.22 & -13.95 & -12.31 \\
\hline & & & $28.25^{\mathrm{w}}$ & & & $51.97^{\mathrm{s}}$ & $52.97^{\mathrm{s}}$ & & \\
\hline I2-a2 & ts3-3 & ts3-3' & 3 & $3^{\prime}$ & I2-a3 & ts3-4 & ts3-4' & 4 & $4^{\prime}$ \\
\hline-5.38 & 48.80 & 54.16 & -15.30 & -13.69 & -8.73 & 51.83 & 55.79 & -14.21 & -11.64 \\
\hline ts1-b & I1-b1 & I1-b2 & ts2-b & & I2-b1 & ts3-2 & ts3-2' & 2 & $2^{\prime}$ \\
\hline \multirow[t]{2}{*}{24.73} & -1.48 & 1.42 & $(55.70)$ & & -5.46 & 48.29 & 53.77 & -16.28 & -14.59 \\
\hline & & & $26.90^{\mathrm{w}}$ & & & $51.88^{\mathrm{s}}$ & $55.66^{\mathrm{s}}$ & & \\
\hline I2-b2 & ts3-5 & ts3-5' & 5 & $5^{\prime}$ & I2-b3 & ts3-6 & ts3-6' & 6 & $6^{\prime}$ \\
\hline-6.80 & 51.06 & 53.71 & -13.55 & -11.40 & -9.35 & 52.23 & 55.66 & -13.81 & -11.83 \\
\hline ts1-c & I1-c1 & I1-c2 & ts2-c & I2-c & I2-c1 & ts3-c1 & ts3-c2 & c1 & c2 \\
\hline \multirow{2}{*}{22.86} & \multirow{2}{*}{0.86} & \multirow{2}{*}{4.71} & $(50.37)$ & \multirow{2}{*}{-3.47} & \multirow{2}{*}{-6.40} & \multirow{2}{*}{48.35} & \multirow{2}{*}{53.76} & \multirow{2}{*}{-19.87} & \multirow{2}{*}{-15.91} \\
\hline & & & $23.36^{\mathrm{w}}$ & & & & & & \\
\hline ts1-d & I1-d1 & I2-d2 & ts2-d & & I2-d1 & ts3-d1 & ts3-d2 & d1 & d2 \\
\hline \multirow{2}{*}{27.26} & \multirow{2}{*}{1.21} & \multirow{2}{*}{1.79} & $(56.23)$ & & \multirow{2}{*}{-9.29} & \multirow{2}{*}{51.69} & \multirow{2}{*}{54.59} & \multirow{2}{*}{-15.31} & \multirow{2}{*}{-13.14} \\
\hline & & & $26.56^{\mathrm{w}}$ & & & & & & \\
\hline
\end{tabular}

\footnotetext{
* To whom correspondence should be addressed. E-mail: $\underline{\text { byx@s,sdu.edu.cn }}$

$\dagger$ Shandong University

Shandong Institute of Light Industry

$\S$ Michigan State University
} 
Notes: ${ }^{a}$ The free rotation of I2-a1/I2-b1 about C6-C11 bond creates another two staggered conformers I2-a2 and I2-a3 /I2-b2 and I2-b3, respectively. I2-a2/I2-b2 is with an anti-orientation between C11-OH and C6-H, and I2-a3/I2-b3 is with an anti-orientation between $\mathrm{C}_{11-\mathrm{CH}_{3}}$ and $\mathrm{C} 6-\mathrm{H}$. I2-a1 (I2-b1) proceeds via ts3-1 and ts3-1' ( ts3-1 and ts3-1') to the corresponding adducts 1 and 1' (2 and 2'), while I2-a2 (I2- a3) proceeds via ts3-3 and ts3-3' ( ts3-4 and ts3-4') to the corresponding adducts 3 and 3' (4 and 4') and I2-b2 (I2-b3) proceeds via ts3-5 and ts3-5' ( ts3-6 and ts3-6') to the corresponding adducts 5 and 5' (6 and 6'). Conformation around C6-C11 in adducts is the same as that in their respective reactants. ${ }^{b}$ Energies of stable structures calculated relative to $4-\mathrm{HNE}+\mathrm{G}$; the transition states relative to their respective reactants. ${ }^{c}$ All energy with zero-point vibrational correction; Numbers in parentheses are the second activation energies without water-catalyzing and ${ }^{w}$ indicates that the activation energy of the second transition state with single water-catalyzing. ${ }^{s}$ stands for the energy calculated with the consideration of the solvent model.

Table S2. Geometrical Character of Two Hydrogen Bonds and $\mathrm{R}_{\mathrm{N}-\mathrm{N}}$ of the Base Pairs

\begin{tabular}{|c|c|c|c|c|}
\hline $\mathrm{X}_{1}$ families & H-bonds & lengths & angles & $R_{N-N}$ \\
\hline \multirow{2}{*}{$1 \mathrm{X}_{1} \mathrm{C}_{1}$} & $\mathrm{O}-\mathrm{H}^{\cdots} \mathrm{N}$ & 1.847 & 177.15 & \multirow{2}{*}{10.323} \\
\hline & $\mathrm{N}-\mathrm{H} \cdots \mathrm{O}$ & 1.838 & 169.52 & \\
\hline \multirow{2}{*}{$2 \mathrm{X}_{1} \mathrm{C}_{1}$} & $\mathrm{O}-\mathrm{H}^{\cdots} \mathrm{N}$ & 1.859 & 177.32 & \multirow{2}{*}{10.273} \\
\hline & $\mathrm{N}-\mathrm{H}^{\cdots} \mathrm{O}$ & 1.835 & 170.62 & \\
\hline \multirow{2}{*}{$1 \mathrm{X}_{1 \mathrm{~s}} \mathrm{~A}^{*}$} & $\mathrm{O}-\mathrm{H}^{\cdots} \mathrm{N}$ & 1.763 & 169.66 & \multirow{2}{*}{10.276} \\
\hline & $\mathrm{N}-\mathrm{H}^{\cdots} \mathrm{O}$ & 1.770 & 175.57 & \\
\hline \multirow{2}{*}{$2 \mathrm{X}_{1 \mathrm{~s}} \mathrm{~A}^{*}$} & $\mathrm{O}-\mathrm{H}^{\cdots} \mathrm{N}$ & 1.768 & 169.84 & \multirow{2}{*}{10.202} \\
\hline & $\mathrm{N}-\mathrm{H} \cdots \mathrm{O}$ & 1.771 & 175.66 & \\
\hline \multirow{2}{*}{$1 \mathrm{X}_{1} \mathrm{~T}^{*}{ }_{1}$} & $\mathrm{O}-\mathrm{H} \cdots \mathrm{O}$ & 1.670 & 171.08 & \multirow{2}{*}{9.843} \\
\hline & $\mathrm{O}-\mathrm{H}^{\cdots} \mathrm{N}$ & 1.909 & 177.98 & \\
\hline \multirow{2}{*}{$2 \mathrm{X}_{1} \mathrm{~T}^{*}{ }_{1}$} & $\mathrm{O}-\mathrm{H}^{\cdots} \mathrm{O}$ & 1.655 & 172.92 & \multirow{2}{*}{8.934} \\
\hline & $\mathrm{O}-\mathrm{H}^{\cdots} \mathrm{N}$ & 2.042 & 174.03 & \\
\hline \multirow{2}{*}{$1 \mathrm{X}_{1} \mathrm{~A}$} & $\mathrm{O}-\mathrm{H}^{\cdots} \cdots \mathrm{N}$ & 1.849 & 162.07 & \multirow{2}{*}{10.869} \\
\hline & $\mathrm{N}-\mathrm{H} \cdots \mathrm{O}$ & 1.853 & 175.09 & \\
\hline \multirow{2}{*}{$2 \mathrm{X}_{1} \mathrm{~A}$} & $\mathrm{O}-\mathrm{H}^{\cdots} \mathrm{N}$ & 1.854 & 169.84 & \multirow{2}{*}{10.861} \\
\hline & $\mathrm{N}-\mathrm{H} \cdots \mathrm{O}$ & 1.848 & 175.66 & \\
\hline \multirow{2}{*}{$1 \mathrm{X}_{1 \mathrm{~s}} \mathrm{~T}_{1}$} & $\mathrm{O}-\mathrm{H} \cdots \mathrm{O}$ & 1.815 & 168.27 & \multirow{2}{*}{8.491} \\
\hline & $\mathrm{N}-\mathrm{H} \cdots \mathrm{O}$ & 1.834 & 166.97 & \\
\hline \multirow{2}{*}{$1 \mathrm{X}_{1} \mathrm{~T}_{2}$} & $\mathrm{O}-\mathrm{H}^{\cdots} \mathrm{O}$ & 1.824 & 167.33 & \multirow{2}{*}{8.295} \\
\hline & $\mathrm{N}-\mathrm{H} \cdots \mathrm{O}$ & 1.847 & 163.57 & \\
\hline \multirow{2}{*}{$2 \mathrm{X}_{1 \mathrm{~s}} \mathrm{~T}_{1}$} & $\mathrm{O}-\mathrm{H} \cdots \mathrm{O}$ & 1.815 & 168.27 & \multirow{2}{*}{8.491} \\
\hline & $\mathrm{N}-\mathrm{H}^{\cdots} \cdots \mathrm{O}$ & 1.835 & 166.97 & \\
\hline \multirow{2}{*}{$2 \mathrm{X}_{1} \mathrm{~T}_{2}$} & $\mathrm{O}-\mathrm{H}^{\cdots} \mathrm{O}$ & 1.828 & 168.19 & \multirow{2}{*}{8.251} \\
\hline & $\mathrm{N}-\mathrm{H} \cdots \mathrm{O}$ & 1.845 & 163.85 & \\
\hline
\end{tabular}




\begin{tabular}{|c|c|c|c|c|}
\hline $\mathrm{X}_{2}$ families & H-bonds & lengths & angles & $R_{N-N}$ \\
\hline \multirow[t]{2}{*}{$1 \mathrm{X}_{2} \mathrm{C}_{2}$} & $\mathrm{O}-\mathrm{H}^{\cdots} \cdots \mathrm{O}$ & 1.837 & 178.05 & 10.342 \\
\hline & $\mathrm{N}-\mathrm{H} \cdots \mathrm{O}$ & 1.967 & 170.70 & \\
\hline \multirow[t]{2}{*}{$1 \mathrm{X}_{2} \mathrm{~A}_{\mathrm{f}}$} & $\mathrm{O}-\mathrm{H}^{\cdots} \mathrm{N}$ & 1.882 & 178.82 & 11.919 \\
\hline & $\mathrm{N}-\mathrm{H} \cdots \mathrm{O}$ & 2.062 & 153.05 & \\
\hline \multirow[t]{2}{*}{$1 \mathrm{X}_{2} \mathrm{~T}_{2}$} & $\mathrm{O}-\mathrm{H}^{\cdots} \mathrm{O}$ & 1.837 & 178.78 & 10.325 \\
\hline & $\mathrm{O}-\mathrm{H}^{\cdots} \cdots \mathrm{O}$ & 1.778 & 161.55 & \\
\hline \multirow[t]{2}{*}{$1 \mathrm{X}_{2} \mathrm{~A}$} & $\mathrm{O}-\mathrm{H}^{\cdots} \cdots \mathrm{N}$ & 1.923 & 174.10 & 12.085 \\
\hline & $\mathrm{N}-\mathrm{H}^{\cdots} \mathrm{O}$ & 2.167 & 152.61 & \\
\hline \multirow[t]{2}{*}{$1 \mathrm{X}_{2} \mathrm{~T}_{1 \mathrm{f}}$} & $\mathrm{O}-\mathrm{H}^{\cdots} \mathrm{O}$ & 1.928 & 167.25 & 10.396 \\
\hline & $\mathrm{N}-\mathrm{H} \cdots \mathrm{O}$ & 1.921 & 168.50 & \\
\hline \multirow[t]{3}{*}{$1 \mathrm{X}_{2} \mathrm{~T}_{2}$} & $\mathrm{O}-\mathrm{H}^{\cdots} \mathrm{O}$ & 1.933 & 168.44 & 10.283 \\
\hline & $\mathrm{N}-\mathrm{H} \cdots \mathrm{O}$ & 1.914 & 168.74 & \\
\hline & $\mathrm{N}-\mathrm{H} \cdots \mathrm{O}$ & 1.789 & 178.97 & \\
\hline \multirow[t]{2}{*}{$\mathrm{GC}$} & $\mathrm{N}-\mathrm{H} \cdots \mathrm{N}$ & 1.934 & 177.40 & 9.050 \\
\hline & $\mathrm{N}-\mathrm{H}^{\cdots} \cdots \mathrm{O}$ & 1.920 & 178.40 & \\
\hline
\end{tabular}

Notes: ${ }^{a}$ Each bond is characterized by the distance between the hydrogen atom and the corresponding acceptor atom, the bond lengths and the angles are in $\AA$ and degree, respectively. ${ }^{b} \mathrm{R}_{\mathrm{N}-\mathrm{N}}$ represents the distance between two nitrogen atoms of base pairs which are connected with deoxyribose unit in DNA (See dot line in Figure S3).

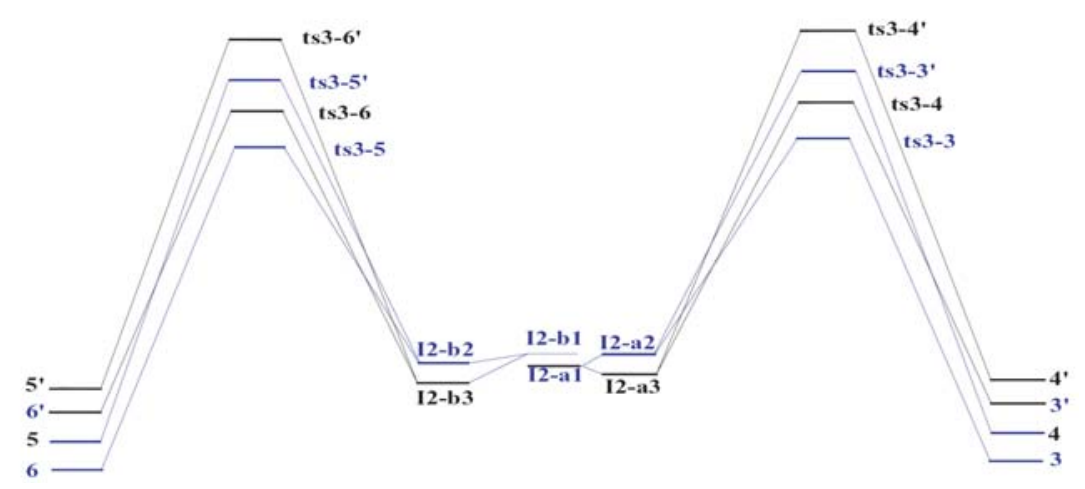

Figure. S1. Schematic illustration of the energy profile of the third step for the reaction of S-4HNE with Guanine. Energies of the transition states are calculated relative to their respective reactants, while those of stable structures are calculated relative to S-4-HNE plus G. The free rotation of I2-a1 (I2-b1) about C6-C11 bond creates another two staggered conformers I2-a2 and I2-a3 (I2-b2 and I2-b3), respectively. I2-a2/I2-b2 is with an anti-orientation between $\mathrm{C} 11-\mathrm{OH}$ and $\mathbf{C} 6-\mathrm{H}$, and $\mathbf{I 2}-\mathbf{a} 3 / \mathbf{I} 2-\mathbf{b} 3$ is with an anti-orientation between $\mathrm{C} 11-\mathrm{CH}_{3}$ and $\mathrm{C} 6-\mathrm{H}$. The detailed geometries are described in Figure S3 B and C. 


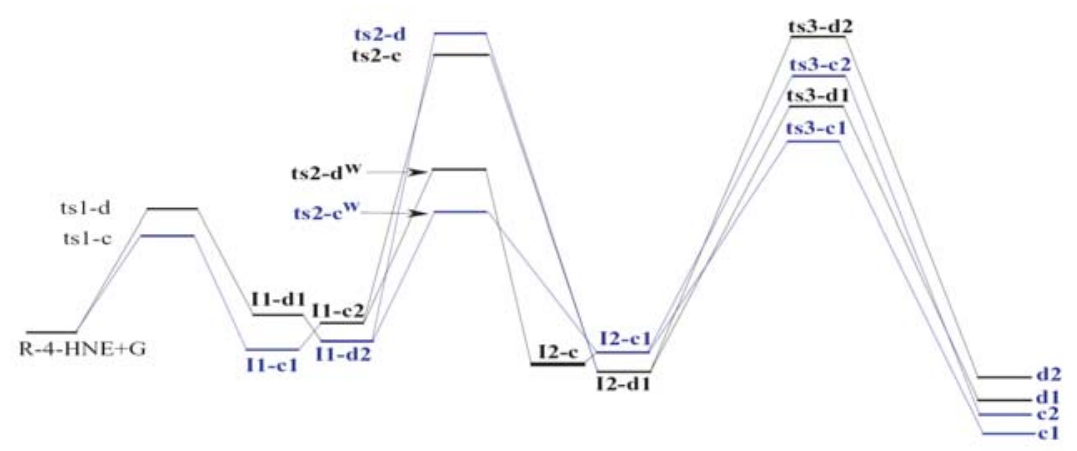

Figure. S2. Schematic illustration of the energy profile for the reaction of R-4HNE with Guanine. Energies of the transition states are calculated relative to their respective reactants, while those of stable structures are calculated relative to R-4-HNE plus G. Conformation around $\mathrm{C} 6-\mathrm{C} 11$ in $\mathbf{I 2 - c 1 / I 2 - d 1}$ is with anti-orientation between $\mathrm{C} 11-\mathrm{H}$ and $\mathrm{C} 6-\mathrm{H}$. The detailed geometries are described in Figure S4. 
A) The complete structures along the formation of adducts 1, 1', 2 and 2'. Conformation around $\mathrm{C} 6-\mathrm{C} 11$ in $\mathbf{I} 2-\mathbf{a 1} / \mathbf{I} 2-\mathbf{b} 1$ is with anti-orientation between $\mathrm{C} 11-\mathrm{H}$ and $\mathrm{C} 6-\mathrm{H}$ and thus conformation around C6-C11 in the corresponding adducts is the same as that in I2-a1/I2-b1.
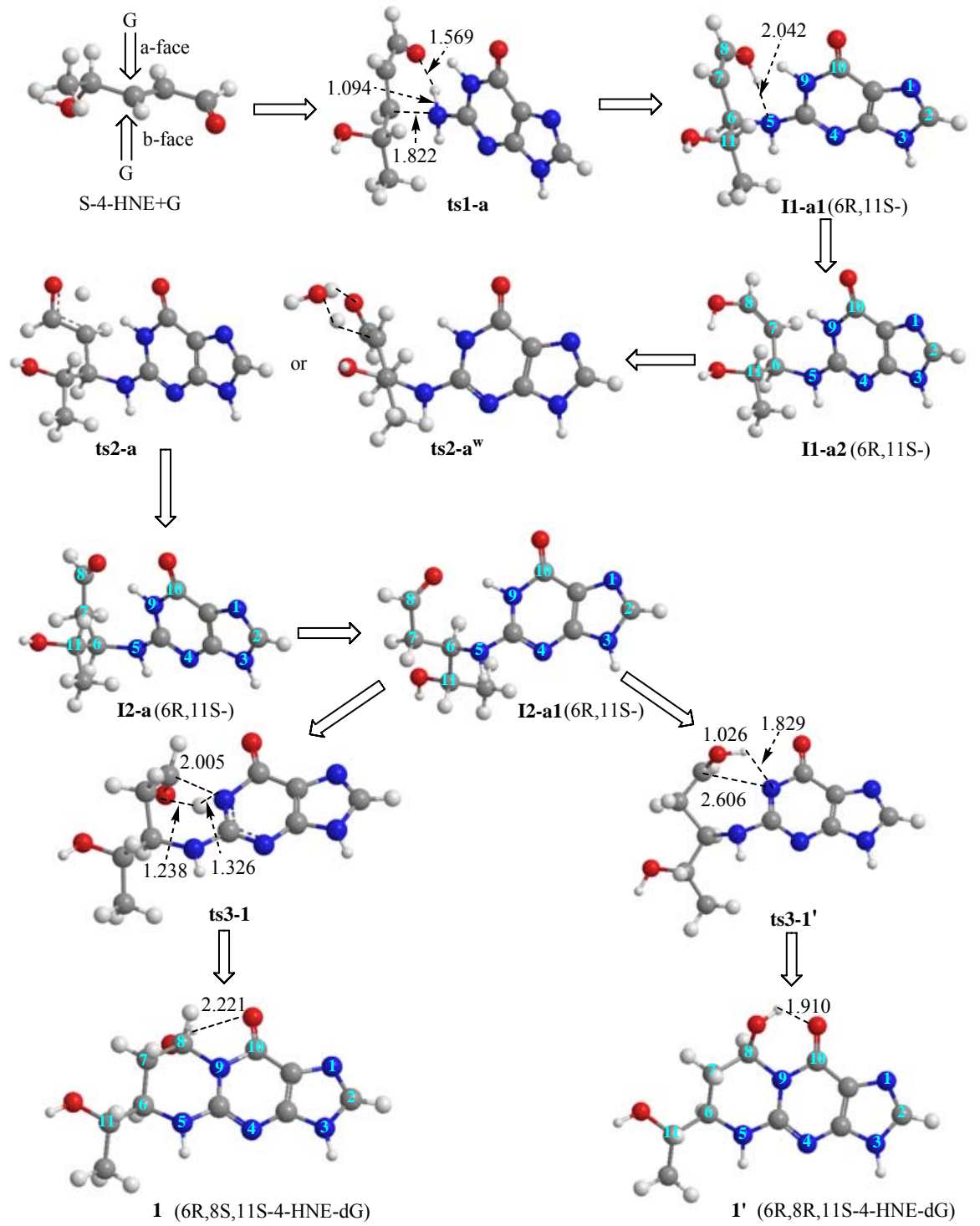

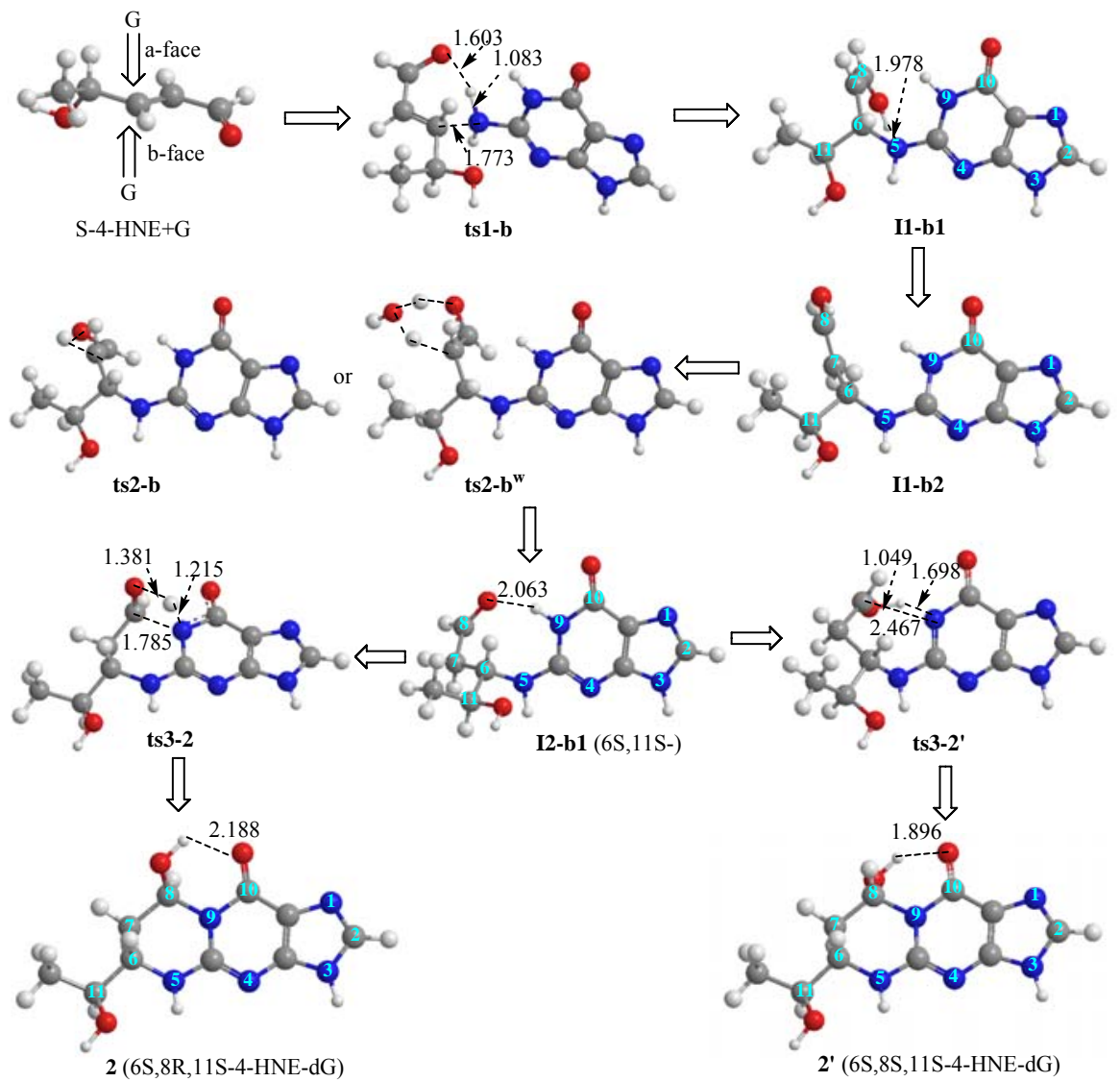
B) The optimized structures of the third step along the formation of adducts 3, 3', 4 and 4' are as follows. Conformation around $\mathrm{C} 6-\mathrm{C} 11$ in $\mathbf{I 2 - a 2} / \mathbf{I 2}-\mathbf{b} 2$ is with anti-orientation between $\mathrm{C} 11-\mathrm{OH}$ and $\mathrm{C} 6-\mathrm{H}$ and thus conformation around $\mathrm{C} 6-\mathrm{C} 11$ in the corresponding adducts is the same as that in I2-a2/I2-b2.

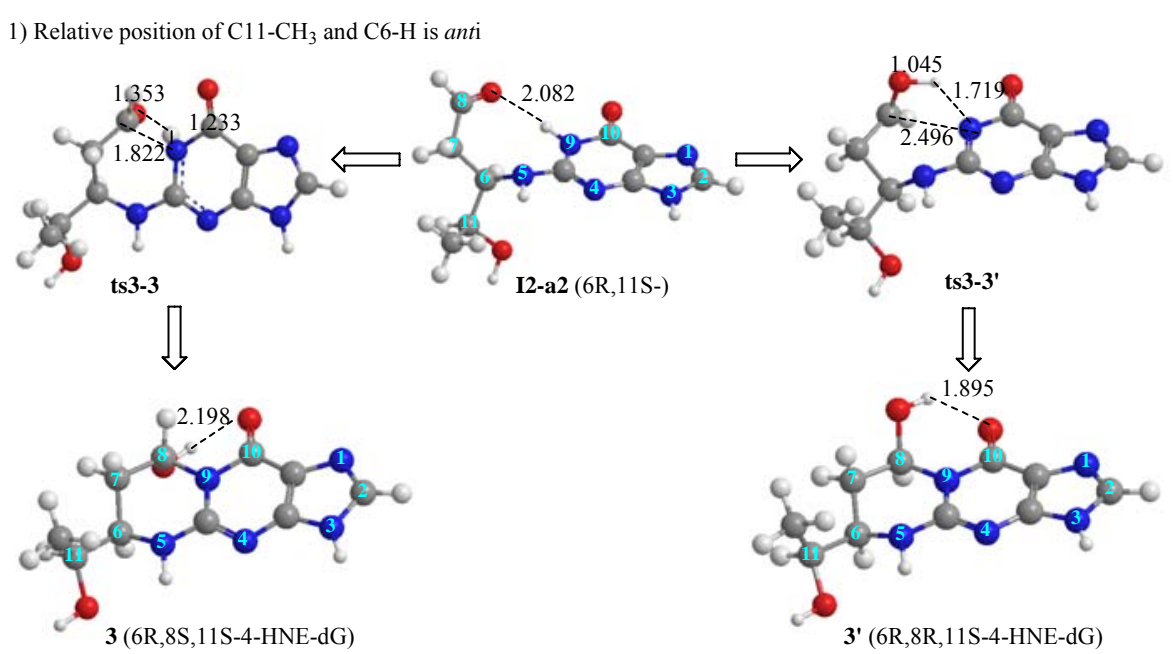

2) Relative position of $\mathrm{C} 11-\mathrm{OH}$ and $\mathrm{C} 6-\mathrm{H}$ is anti
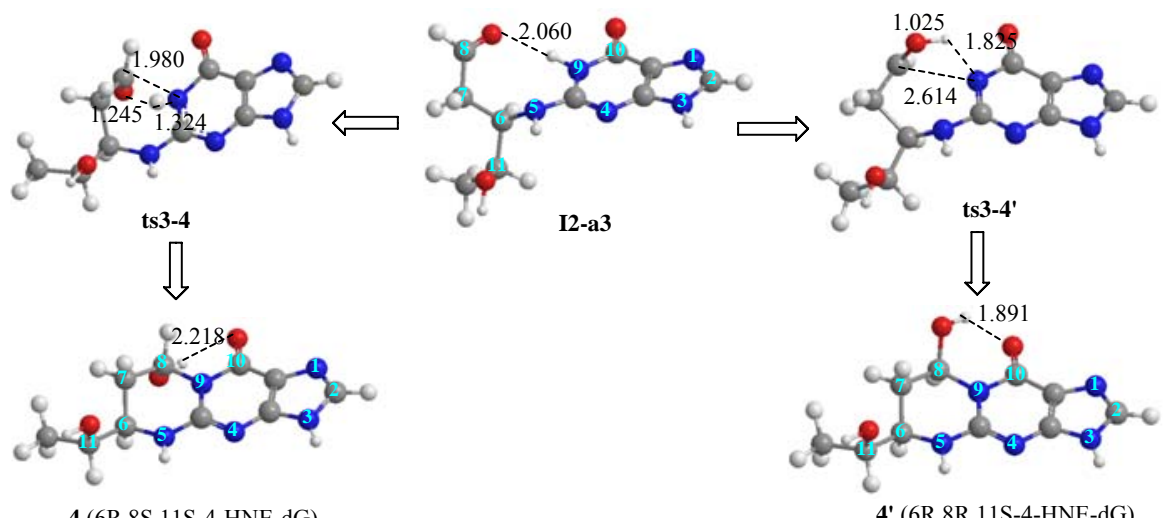

4 (6R,8S,11S-4-HNE-dG)

4' (6R,8R,11S-4-HNE-dG) 
C) The optimized structures of the third step along the formation of adducts 5, 5', 6 and 6' are

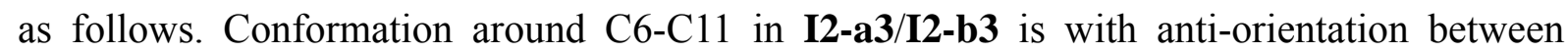
$\mathrm{C} 11-\mathrm{CH}_{3}$ and $\mathrm{C} 6-\mathrm{H}$ and thus conformation around $\mathrm{C} 6-\mathrm{C} 11$ in the corresponding adducts is the same as that in I2-a3/I2-b3.
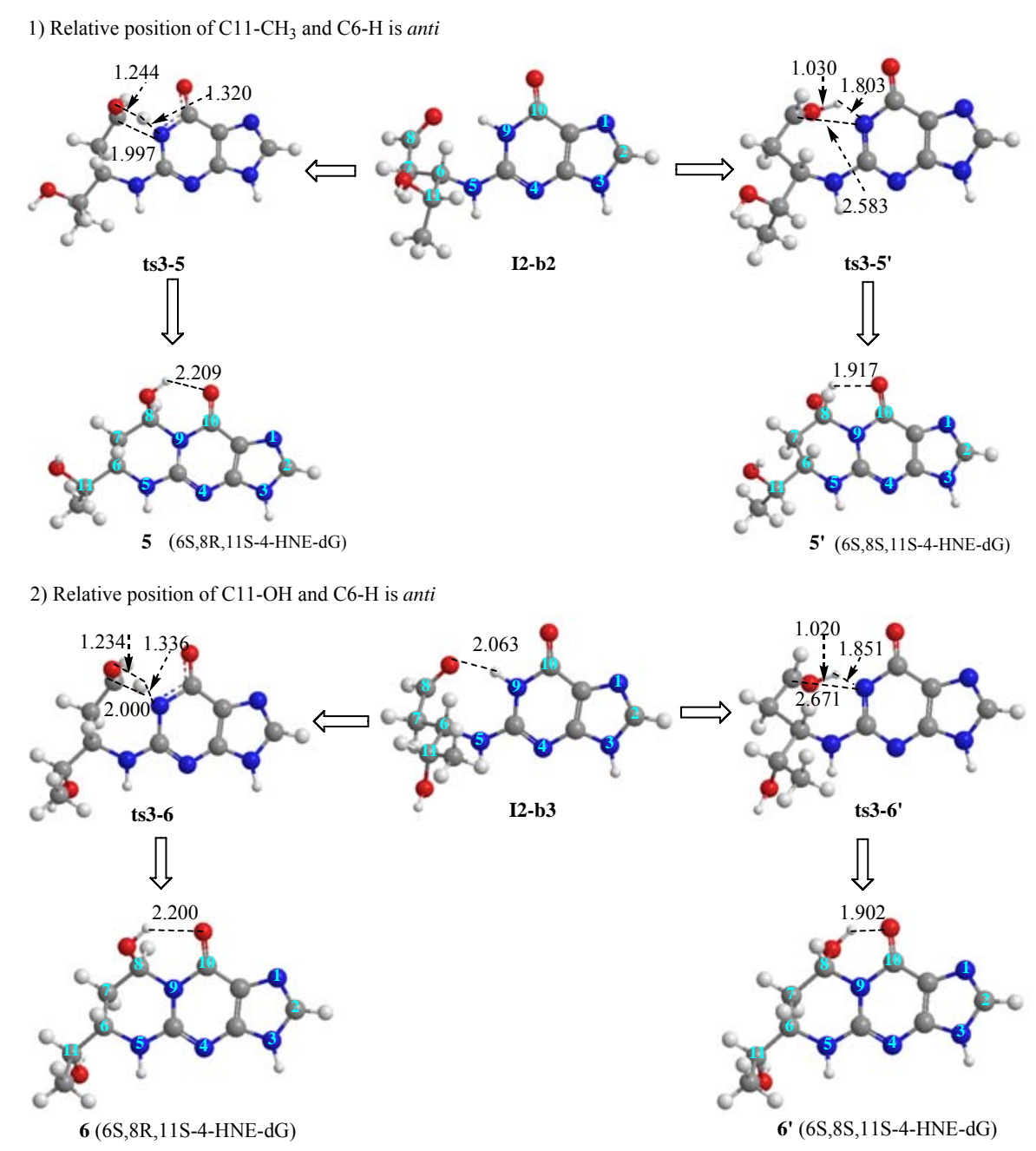

Figure S3. All optimized structures of the Reaction of S-4-HNE with Guanine. Conformation around C6-C11 in I2-a1/I2-b1 is with anti-orientation between $\mathrm{C} 11-\mathrm{H}$ and C6-H, while that in I2-a2/I2-b2 is with anti-orientation between $\mathrm{C} 11-\mathrm{OH}$ and $\mathrm{C} 6-\mathrm{H}$ and that

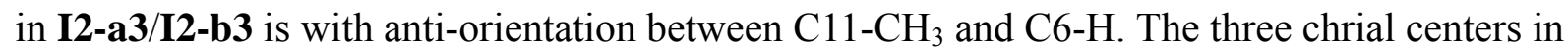
$\mathbf{1}, \mathbf{3}$ and $\mathbf{4}$ are $(6 \mathrm{R}, 8 \mathrm{~S}, 11 \mathrm{~S})$ and that in $\mathbf{1}^{\prime}, \mathbf{3}^{\prime}$ and $\mathbf{4}^{\prime}$ are $(6 \mathrm{R}, 8 \mathrm{R}, 11 \mathrm{~S})$, while the three chrial centers in 2, 5 and $\mathbf{6}$ are $(6 \mathrm{~S}, 8 \mathrm{R}, 11 \mathrm{~S}))$ and that in $\mathbf{2}^{\prime}, \mathbf{5}^{\prime}$ and $\mathbf{6}^{\prime}$ are $(6 \mathrm{~S}, 8 \mathrm{~S}, 11 \mathrm{~S})$. Since the stereochemistry of $\mathrm{C} 6$ and $\mathrm{C} 8$ in $\mathbf{1}, \mathbf{3}, \mathbf{4}, \mathbf{2}, \mathbf{5}$ and $\mathbf{6}$ is trans, they are denoted by trans-4-HNE-dG adducts for simplicity. Conversely, the stereochemistry of C6 and C8 in 1', 3', 4', 2', 5' and 6' is cis, they are denoted by cis-4-HNE-dG adducts. 

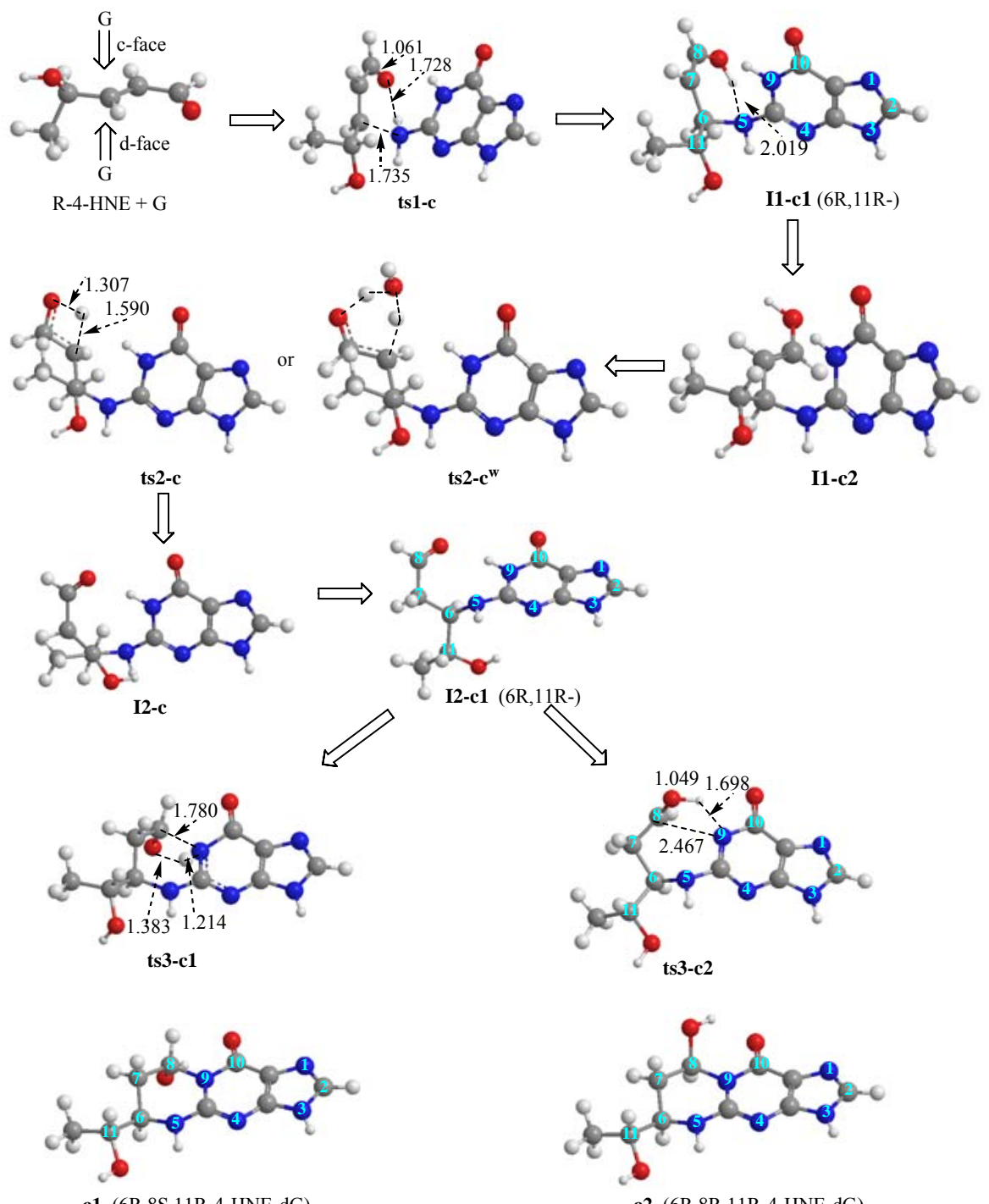

c1 $(6 \mathrm{R}, 8 \mathrm{~S}, 11 \mathrm{R}-4-\mathrm{HNE}-\mathrm{dG})$

c2 (6R,8R,11R-4-HNE-dG) 

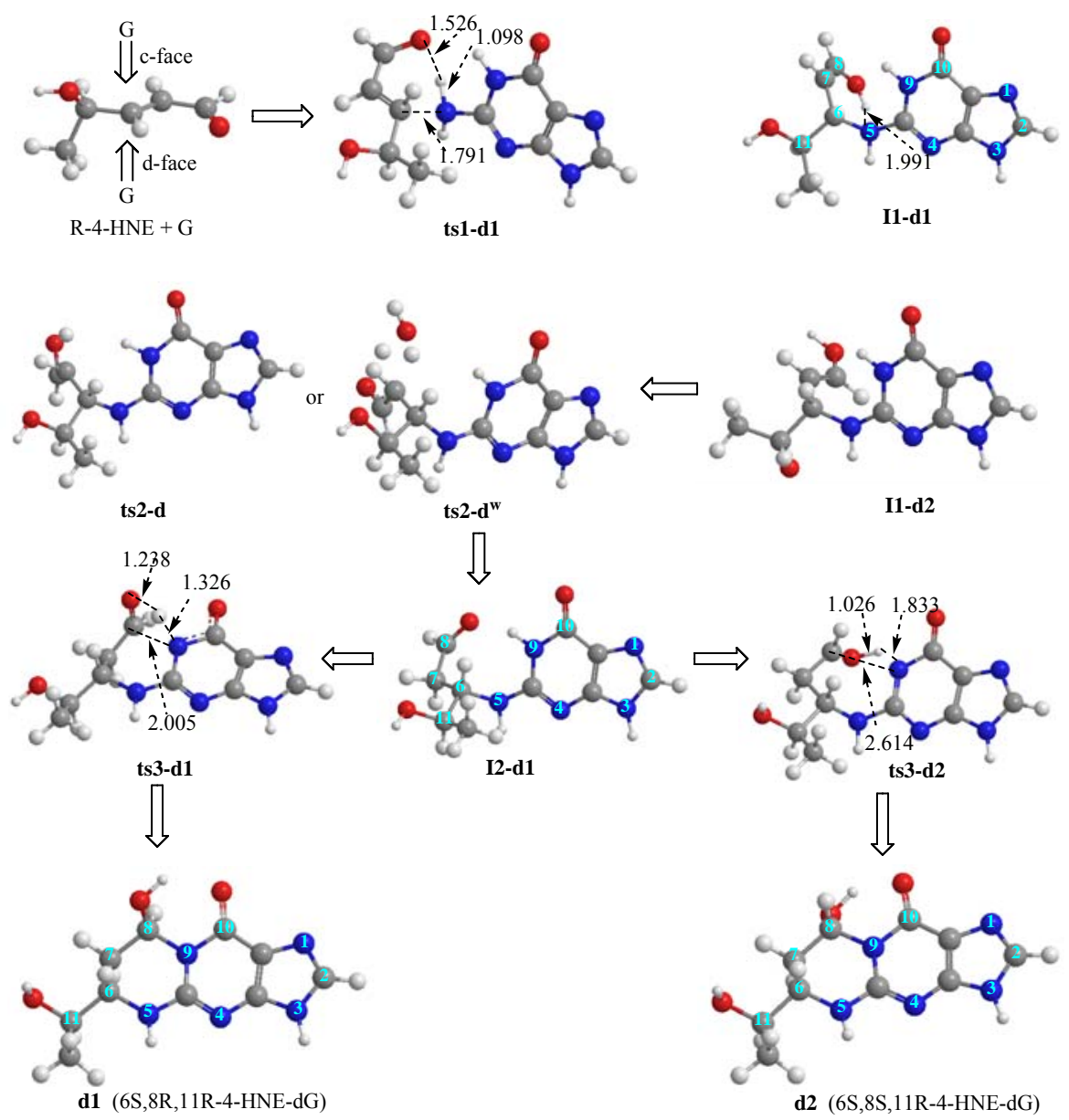

Figure S4. The Optimized Geometries of the Reaction of R-4-HNE with Guanine. Conformation around $\mathrm{C} 6-\mathrm{C} 11$ in $\mathbf{I 2 - c 1 / I 2 - d 1}$ is with anti-orientation between $\mathrm{C} 11-\mathrm{H}$ and C6-H. The three chiral centers in $\mathbf{c 1}$ is $(6 \mathrm{R}, 8 \mathrm{~S}, 11 \mathrm{R})$ and that in $\mathbf{d 1}$ is $(6 \mathrm{~S}, 8 \mathrm{R}, 11 \mathrm{R})$. Since the stereochemistry of $\mathrm{C} 6$ and $\mathrm{C} 8$ in $\mathrm{c} 1$ and $\mathrm{d} 1$ is trans, they are denoted by trans-4-HNE-dG adducts. The three chiral centers in $\mathbf{c} 2$ is $(6 \mathrm{R}, 8 \mathrm{R}, 11 \mathrm{R})$ and that in $\mathbf{d} 2$ is $(6 \mathrm{~S}, 8 \mathrm{~S}, 11 \mathrm{R})$. Since the stereochemistry of C6 and C8 in $\mathbf{c} 2$ and $\mathbf{d} 2$ is cis, they are denoted by cis-4-HNE-dG adducts. 


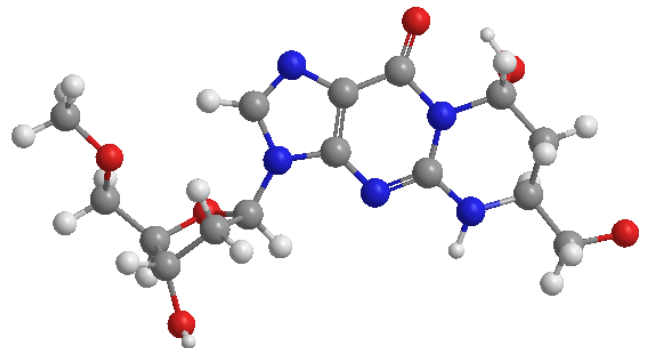

a

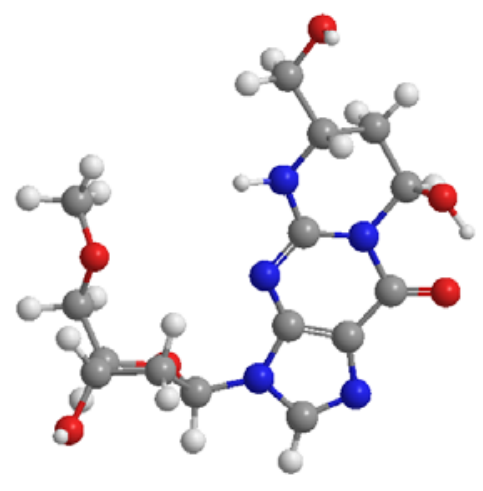

b

Relative energy: 0

$2.81 \mathrm{kcal} / \mathrm{mol}$

Figure S5. The conformation of 4-HNE-dG with respect to the sugar phosphate backbone and their relative energy. a, the base is in the anti orientation with respect to the sugar phosphate backbone; $b$, the base is in the syn orientation with respect to the sugar phosphate backbone. 
1) $X_{1}$ family
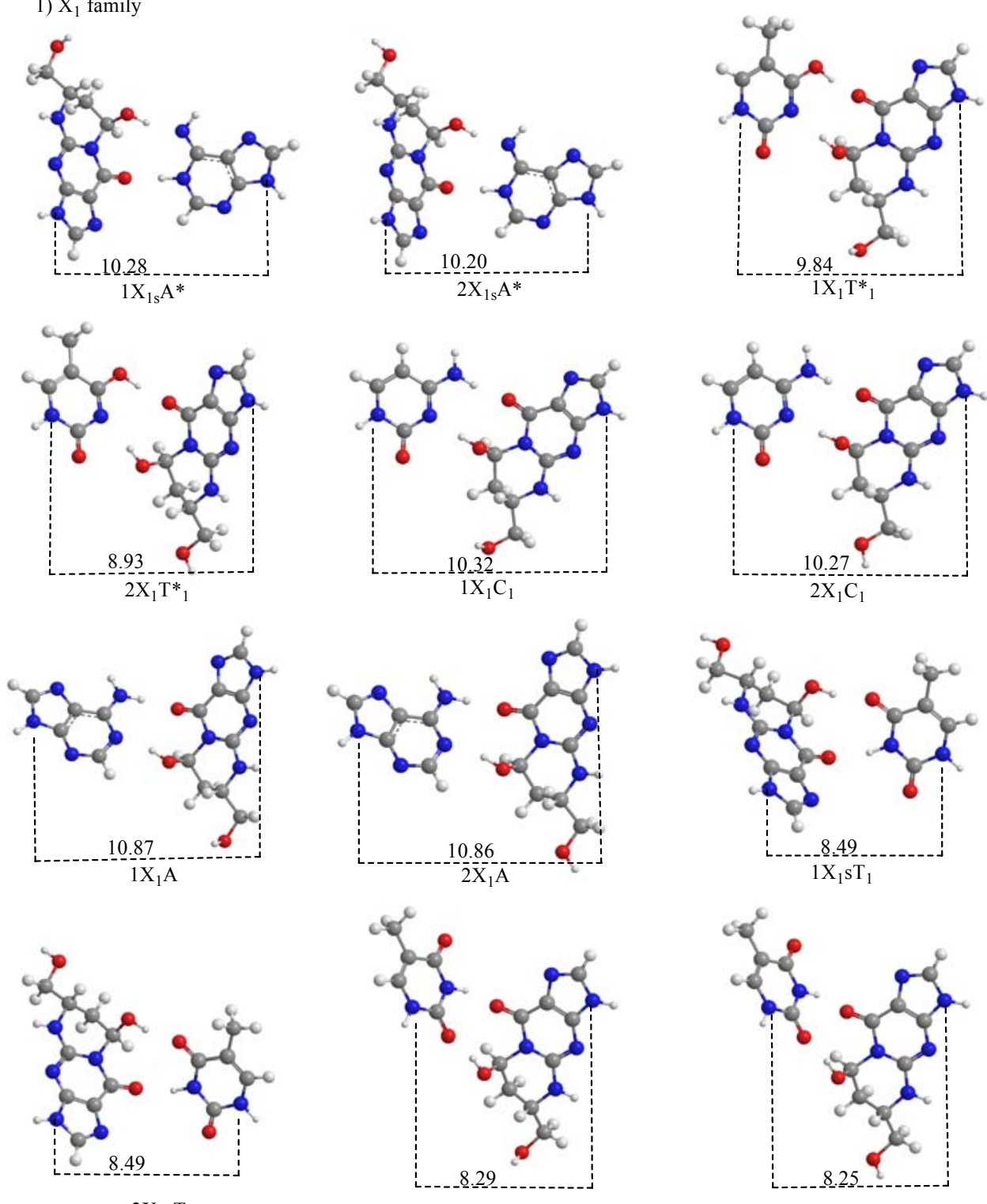

$1 \mathrm{X}_{1} \mathrm{~T}_{2}$

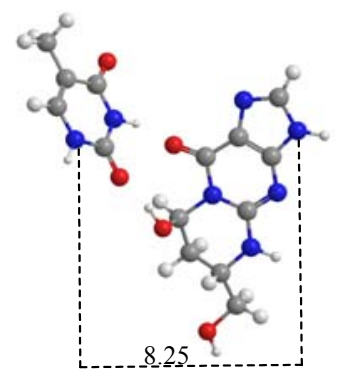

$2 \mathrm{X}_{1} \mathrm{~T}_{2}$
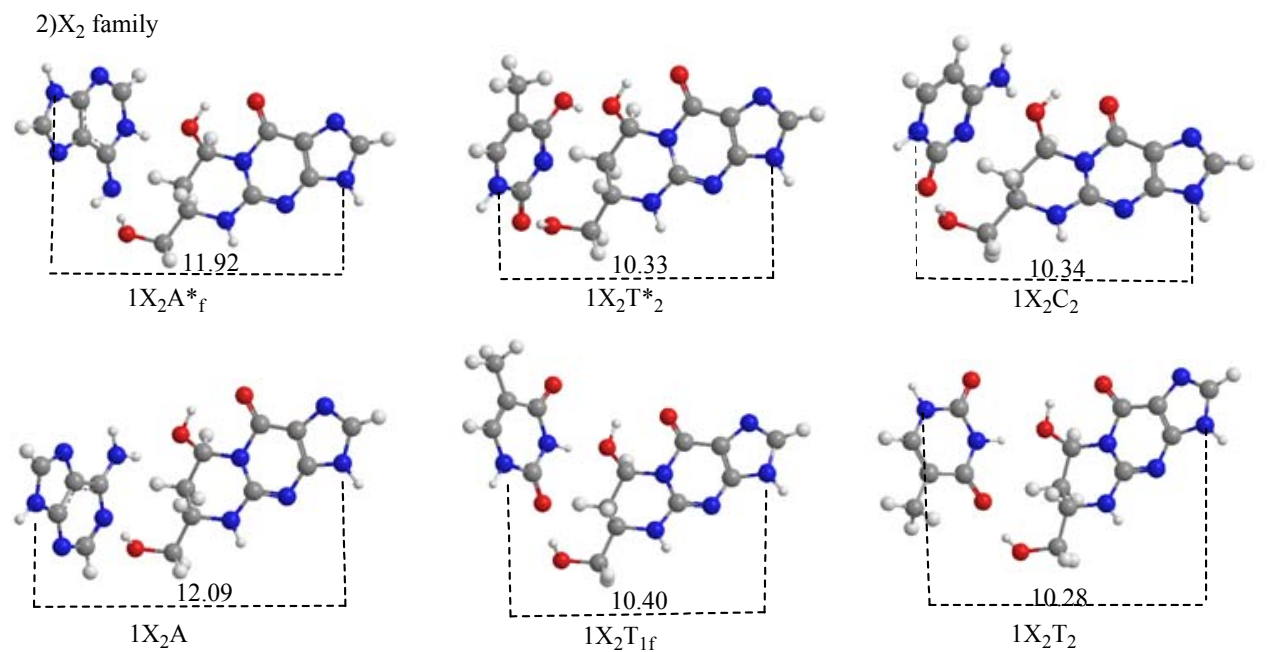
Figure S6. Optimized geometry and $\mathrm{R}_{\mathrm{N}-\mathrm{N}}$ of the $\mathrm{XA}^{*}, \mathrm{XT}^{*}, \mathrm{XC}, \mathrm{XA}$ and $\mathrm{XT}$, calculated at b3lyp/6-31+G* The values on the dot line refer to the computed $\mathrm{R}_{\mathrm{N}-\mathrm{N}}$ values (in $\AA$ ) of the base pairs (distances between two nitrogen atoms of base pairs, where are connected with deoxyribose unit in DNA). All structures of $\mathrm{X}$ in the Figure are in the anti conformations, unless otherwise noted by subscript s. Notations in this Figure represent the binding site and the conformation of the base for a given pair. Subscripts (digit, s or f) stand for the binding sites, conformation around the glycosidic bond or the orientation of the base. For example, $1 \mathrm{X}_{1 \mathrm{~s}} \mathrm{~A} *$ indicates that $1 \mathrm{X}$ adopts the syn-conformation to pair with normal Watson-Crick face of $A^{*}$ by site $1 ; 1 \mathrm{X}_{2} \mathrm{~T}_{1 \mathrm{f}}$ indicates that $1 \mathrm{X}_{2}$ adopts the anti-conformation to pair with $\mathrm{T}_{1}$ and $\mathrm{T}_{1}$ should be flipped to facilitate the binding site of $1 \mathrm{X}$ simultaneously.
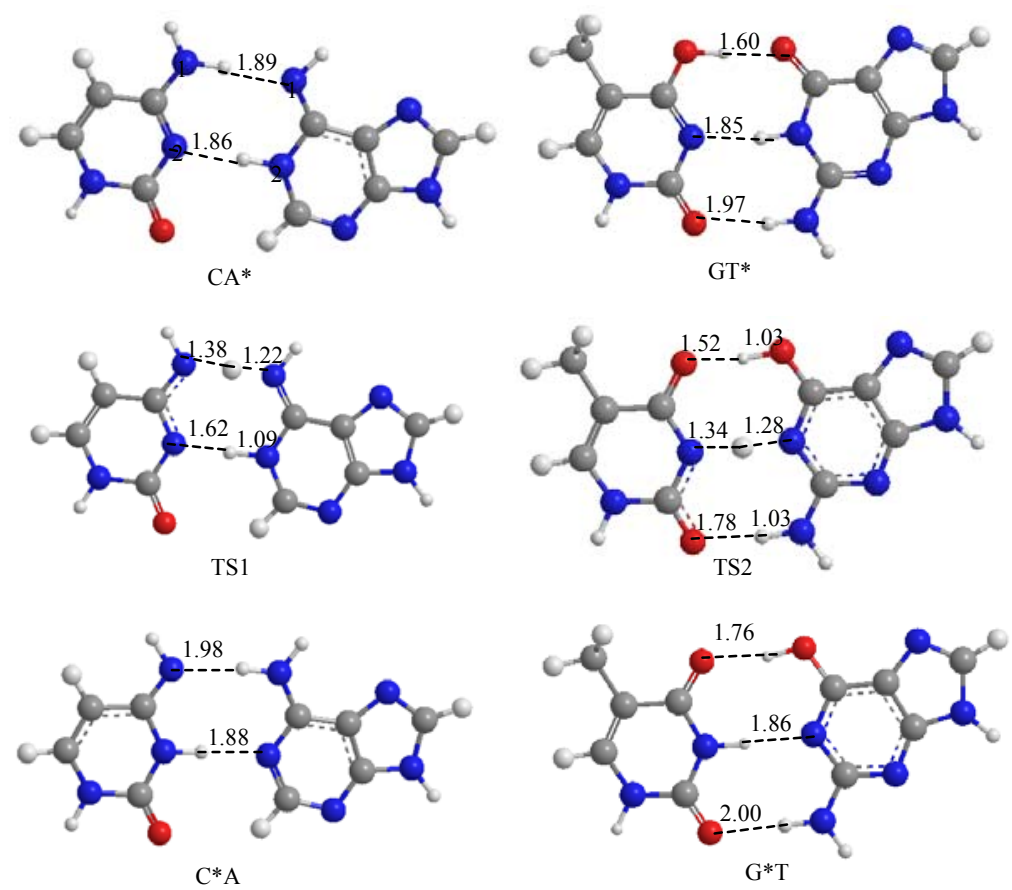

Figure S7. Optimized Geometry of $C^{*} A, C A^{*}, G^{*}, G^{*} T$ Base Pairs as well as the Transition state of $\mathrm{C}^{*} \mathrm{~A} \rightarrow \mathrm{CA}^{*}(\mathrm{TS} 1)$ and $\mathrm{GT}^{*} \rightarrow \mathrm{G}^{*} \mathrm{~T}(\mathrm{TS} 2)$. The Numbers refer to the computed H-bond distances. All H-bond lengths are in $\AA$. 